\title{
Article \\ Genome-Wide Identification and Expression Analysis of the 14-3-3 Gene Family in Mango (Mangifera indica L.)
}

\author{
Liming Xia ${ }^{\dagger}$, Xinhua He ${ }^{\dagger} \mathbb{D}$, Xing Huang, Haixia Yu, Tingting Lu, Xiaojie Xie, Xuemei Zeng, Jiawei Zhu \\ and Cong Luo*
}

check for updates

Citation: Xia, L.; He, X.; Huang, X.; Yu, H.; Lu, T.; Xie, X.; Zeng, X.; Zhu, J.; Luo, C. Genome-Wide Identification and Expression Analysis of the 14-3-3 Gene Family in Mango (Mangifera indica L.). Int. J.

Mol. Sci. 2022, 23, 1593.

https: / /doi.org/10.3390/ ijms23031593

Academic Editor: Hikmet Budak

Received: 5 January 2022

Accepted: 28 January 2022

Published: 29 January 2022

Publisher's Note: MDPI stays neutral with regard to jurisdictional claims in published maps and institutional affiliations.

Copyright: (C) 2022 by the authors. Licensee MDPI, Basel, Switzerland. This article is an open access article distributed under the terms and conditions of the Creative Commons Attribution (CC BY) license (https:// creativecommons.org/licenses/by/ $4.0 /)$

\author{
State Key Laboratory for Conservation and Utilization of Subtropical Agro-Bioresources, College of Agriculture, \\ Guangxi University, 100 East Daxue Road, Nanning 530004, China; xialimingguangxi@163.com (L.X.); \\ honest66222@163.com (X.H.); xinghuangkeys@163.com (X.H.); yuhaixia0201@163.com (H.Y.); \\ lutting4040@163.com (T.L.); xiexiaojie0827@126.com (X.X.); zengxuemei1228@163.com (X.Z.); \\ zhujiaweiii1206@163.com (J.Z.) \\ * Correspondence: 22003luocong@gxu.edu.cn \\ + These authors contributed equally to this work.
}

\begin{abstract}
Members of the Mi14-3-3 gene family interact with target proteins that are widely involved in plant hormone signal transduction and physiology-related metabolism and play important roles in plant growth, development and stress responses. In this study, 14-3-3s family members are identified by the bioinformatic analysis of the mango (Mangifera indica L.) genome. The gene structures, chromosomal distributions, genetic evolution, and expression patterns of these genes and the physical and chemical properties and conserved motifs of their proteins are analysed systematically. The results identified 16 members of the 14-3-3 genes family in the mango genome. The members were not evenly distributed across the chromosomes, and the gene structure analysis showed that the gene sequence length and intron number varied greatly among the different members. Protein sequence analysis showed that the Mi14-3-3 proteins had similar physical and chemical properties and secondary and tertiary structures, and protein subcellular localization showed that the Mi14-3-3 family proteins were localized to the nucleus. The sequence analysis of the Mi14-3-3s showed that all Mi14-3-3 proteins contain a typical conserved PFAM00244 domain, and promoter sequence analysis showed that the Mi14-3-3 promoters contain multiple hormone-, stress-, and light-responsive cisregulatory elements. Expression analysis showed that the 14-3-3 genes were expressed in all tissues of mango, but that their expression patterns were different. Drought, salt and low temperature stresses affected the expression levels of 14-3-3 genes, and different 14-3-3 genes had different responses to these stresses. This study provides a reference for further studies on the function and regulation of Mi14-3-3 family members.
\end{abstract}

Keywords: mango; 14-3-3 gene family; genome-wide identification; expression characteristics

\section{Introduction}

The 14-3-3s family is composed of proteins encoded by multiple genes (including multiple isomers encoded by homologous genes) that are found in a wide variety of eukaryotes. 14-3-3 proteins promote or inhibit the activities of various enzymes, serve as bridges for protein-protein interactions, and regulate cell protein levels and locations. 14-3-3 proteins, which are important regulatory proteins, also play crucial roles in the signalling of several hormones involved in normal plant-development-related metabolism and stress responses [1]. In recent years, researchers have made breakthroughs concerning the involvement of 14-3-3 proteins in the regulation of flower formation, abiotic stress responses, energy metabolism, and signal transduction in plants, and 14-3-3 proteins constitute a popular research topic in the field of plant signalling.

14-3-3s are involved in both the photoperiod and the gibberellin (GA) pathways in plants. The florigen homologue SFT in tomato has been found to interact with 14-3-3 
proteins [2]. The overexpression of PvGF14b, PvGF14c and PvGF14e from Phyllostachys violascens significantly delays the flowering time of transgenic Arabidopsis thaliana. These results show that at least three PvGF14 genes are involved in the flowering network of bamboo; in addition, through its interaction with FLOWERING LOCUS T (PvFT), PvGF14c has been found to act as a negative regulator of flowering in Phyllostachys violascens [3]. In the cytoplasm of rice, Hd3a interacts with 14-3-3s, and the Hd3a-14-3-3 complex interacts with a rice FLOWERING LOCUS $D(F D)$ homologue, OsFD1, to form a heterohexameric protein complex called the florigen-activating complex (FAC). The interaction of TERMINAL FLOWER 1-like (TFL1) with FD and 14-3-3 binding sites suggests that TFL1 creates a similar compound (FRC) to inhibit FT. In the meristem, RCN can interact with 14-3-3s and OsFD1, and four RICE CENTRORADIALIS genes (RCNs) interact with GF14b, GF14c, GF14e and GF14f. However, Hd3a does not interact directly with OsFD1 in vitro, so 14-3-3 proteins mediate the interaction between $H d 3 a$ and OsFD1 [4-6].

Increasingly, in-depth studies on the functions of 14-3-3 proteins have revealed that these proteins play roles in plant responses to drought, salt and cold stresses by regulating stomatal opening, root movement, signalling hormones, physiology-related metabolism and stress responses [7-11]. Although 14-3-3 proteins in plants have a highly conserved target-binding domain, several studies have shown that different 14-3-3 subtypes can modulate different targets at different locations under different abiotic stresses [12]. In rice, 14-3-3 proteins regulate the rice glycometabolism pathway by interacting with MYBS2 to regulate $\alpha$-amylase ( $\alpha$-amy) in the nuclear cytoplasmic transport pathway [13]. OsGF14c, a 14-3-3 subtype, positively regulates the drought resistance of rice seedlings. OsGF14b negatively regulates drought resistance by altering drought-stress-related parameters (peroxidase activity and malondialdehyde (MDA), proline and soluble sugar levels) [14,15]. The overexpression of GF14c in rice results in delayed flowering and early flowering in a functional deletion (T-DNA insertion) mutant, suggesting that GF14c is a flowering suppressor [16]. The downstream MADS-box transcription factor 15-like (OsMADS15) gene is then activated to induce flowering in rice [17]. Under salt stress, the GhGRF3, GhGRF4, GhGRF5, GhGRF7 and GhGRF16 genes have been found to be downregulated in the leaves of cotton [18].

To date, different numbers of 14-3-3 genes have been identified in a variety of plant species, including 13 in Arabidopsis [19], 8 in rice [20], 16 in soybean [21], 17 in tobacco [22], 9 in poplar [23], 18 in apple [24] and 8 in sweet orange [25]. Until now, however, little information has been available about 14-3-3 family members in mango. Mango is an important tropical and subtropical fruit tree species that is affected by various environmental factors during its growth and development. Plant 14-3-3 proteins are involved in proteinprotein interactions and play important roles in diverse biological processes. In this study, we identify sixteen Mi14-3-3 gene family members from a mango genome database and analysed their physical and chemical properties, chromosomal locations, gene structures, evolutionary relationships, promoter cis-regulatory elements and expression profiles in different tissues and in response to low temperature, drought and salt stress treatments. Our aim is to lay a foundation for future studies of the functions of the Mi14-3-3 genes in mango-flowering-regulation and stress responses.

\section{Results}

\subsection{Genome-Wide Identification of Mi14-3-3 Gene Family Members and Characterization of Their Proteins}

Using the protein sequence of an Arabidopsis 14-3-3 protein family member as bait, we evaluated the conserved domain of the target sequences by bioinformatic analysis and removed the redundant protein sequences with HMMER and SMART online software. Sixteen members of the Mi14-3-3 family were identified from the 'Sijimi' mango genome (unpublished) (Table 1), which is consistent with the number of 14-3-3 proteins found in the published genome of mango (Alfonso) [26]. The lengths of the 14-3-3 genes in mango ranged from 747 to $840 \mathrm{bp}$, the numbers of encoded amino acids ranged from 247 (Mi14- 
3-3-C2) to 278 (Mi14-3-3-I1) amino acids, and the molecular weights (MWs) ranged from $28.08 \mathrm{kD}$ (Mi14-3-3-C2) to $30.97 \mathrm{kD}$ (Mi14-3-3-I1). The results showed that the isoelectric points (pIs) of the Mi14-3-3 proteins were less than 7.0, which indicated that the proteins were acidic, and the grand average of hydropathy (GRAVY) of the Mi14-3-3 proteins was negative, which indicated that the proteins were hydrophilic. The instability indices of all Mi14-3-3 proteins were higher than 40.

Table 1. Information concerning 14-3-3 genes in mango.

\begin{tabular}{|c|c|c|c|c|c|c|c|}
\hline Gene Name & Gene Locus & Chr & aa & pI & II & MW (Da) & Gene Entry Number \\
\hline Mi14-3-3-A1 & $\begin{array}{l}15934509- \\
15936351\end{array}$ & Chr11 & 257 & 4.78 & 47.14 & $29,051.64$ & OK491862 \\
\hline Mi14-3-3-A2 & $\begin{array}{l}8935256- \\
8937263\end{array}$ & Chr12 & 262 & 4.74 & 48.11 & $29,631.29$ & OK491863 \\
\hline Mi14-3-3-B1 & $\begin{array}{l}4489787- \\
4491126\end{array}$ & Chr10 & 252 & 4.83 & 37.22 & $28,431.38$ & OK491864 \\
\hline Mi14-3-3-B2 & $\begin{array}{l}3572447- \\
3574125\end{array}$ & Chr19 & 252 & 4.79 & 39.12 & $28,503.45$ & OK491865 \\
\hline Mi14-3-3-C1 & $\begin{array}{l}4366341- \\
4369386\end{array}$ & Chr16 & 265 & 4.80 & 35.13 & $29,899.64$ & OK491866 \\
\hline Mi14-3-3-C2 & $\begin{array}{l}9746038- \\
9747732\end{array}$ & Chr9 & 247 & 4.85 & 41.86 & $28,078.73$ & OK491867 \\
\hline Mi14-3-3-D1 & $\begin{array}{l}18226835- \\
18229518\end{array}$ & Chr6 & 257 & 4.77 & 46.99 & $29,284.95$ & OK491868 \\
\hline Mi14-3-3-D2 & $\begin{array}{l}1716202- \\
1718844\end{array}$ & Chr13 & 257 & 4.68 & 45.77 & $29,422.24$ & OK491869 \\
\hline Mi14-3-3-E1 & $\begin{array}{l}3882198- \\
3883306\end{array}$ & Chr19 & 261 & 4.68 & 44.49 & $29,583.16$ & OK491870 \\
\hline Mi14-3-3-E2 & $\begin{array}{l}4744386- \\
4745564\end{array}$ & Chr10 & 261 & 4.69 & 51.96 & $29,607.16$ & OK491871 \\
\hline Mi14-3-3-I1 & $\begin{array}{l}2799060- \\
2800971\end{array}$ & Chr4 & 278 & 4.83 & 49.60 & $30,968.14$ & OK491872 \\
\hline Mi14-3-3-I2 & $\begin{array}{l}8264404- \\
8266523\end{array}$ & Chr8 & 267 & 4.93 & 51.64 & $30,230.90$ & OK491873 \\
\hline Mi14-3-3-6A & $\begin{array}{l}364937- \\
367380\end{array}$ & Chr7 & 261 & 4.72 & 48.41 & $29,541.14$ & OK203791 \\
\hline Mi14-3-3-6B & $\begin{array}{l}12389595- \\
12391788\end{array}$ & Chr4 & 261 & 4.76 & 50.54 & $29,376.81$ & OK203792 \\
\hline Mi14-3-3-7A & $\begin{array}{l}4859531- \\
4862214\end{array}$ & Chr10 & 266 & 5.01 & 42.85 & $30,506.27$ & OK491860 \\
\hline Mi14-3-3-7B & $\begin{array}{l}4027530- \\
4010130\end{array}$ & Chr19 & 254 & 4.85 & 45.50 & $28,807.40$ & OK491861 \\
\hline
\end{tabular}

The secondary structures of Mi14-3-3 family proteins were analysed. The secondary structure of a protein is the specific conformation achieved when the backbone atoms of a polypeptide chain are coiled or folded along a certain axis-in other words, the spatial arrangement of atoms in the backbone of a peptide chain (the side chains of the amino acid residues are not involved). These structures generally include $\alpha$-helices, $\beta$ folds, $\beta$-turns, and random crimps. The secondary structures of the $16 \mathrm{Mi14}-3-3$ proteins were analysed with SOPMA software (Table S1). The results showed that the Mi14-3-3 proteins had similar secondary structures, indicating that these proteins may form similar higher-order structures to perform similar functions. The proportion of $\alpha$-helices was the highest $(65.28 \% \sim 3.81 \%)$, followed by the proportion of random coils $(20 \%)$, while the 
proportions of extended strands and $\beta$-turns were the lowest. $\beta$-Turns are common stable secondary structures in polypeptide chains that mainly connect $\alpha$-helices and $\beta$-folds in proteins. Among the 16 14-3-3 proteins of mango, Mi14-3-3-6A was found to comprise $3.07 \% \beta$-turns, and Mi14-3-3-I2 was found to comprise $0.75 \% \beta$-turns. It is speculated that Mi14-3-3-6A may have more changes in the direction of polypeptide chains and a more complex structure than Mi14-3-3-I2. The tertiary structure of a protein is formed by further winding and folding on the basis of the secondary structure and is mainly maintained by hydrophobic interactions between amino acid side chains, hydrogen bonds and electrostatic interactions. To elucidate the mechanism of action of a protein, it is necessary to predict the three-dimensional structure of the protein. Therefore, we used an online software to predict the tertiary structures of the 16 14-3-3 protein family members and found that the proteins that have similar three-dimensional conformations are composed mostly of $\alpha$-helices and have symmetrical spatial structures (Figure 1).

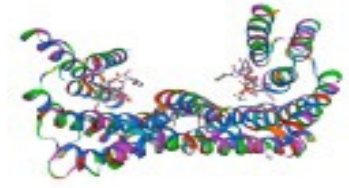

Mi14-3-3-A1

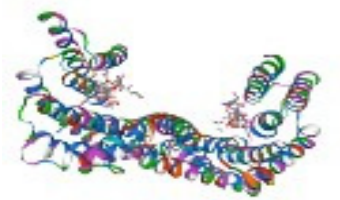

Mi14-3-3-C1

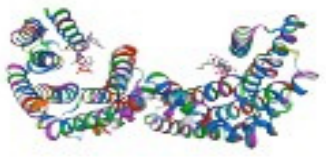

Mi14-3-3-E1

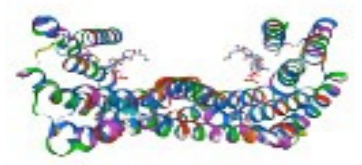

Mi14-3-3-6A

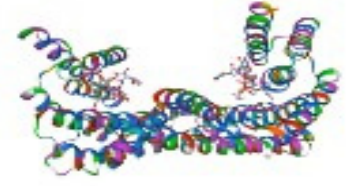

Mi 14-3-3-A2

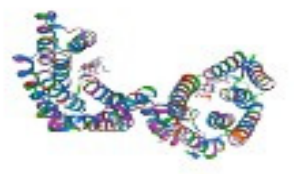

Mi14-3-3-C2

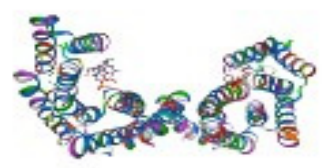

Mi 14-3-3-E2
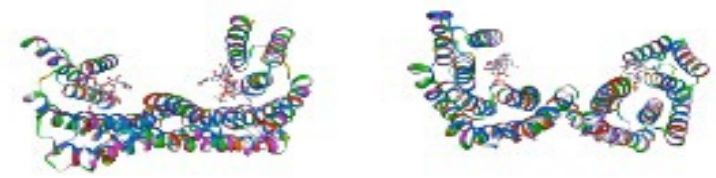

Mi 14-3-3-6B

Mi 14-3-3-B1

Mi14-3-3-D1

Mi14-3-3-I1

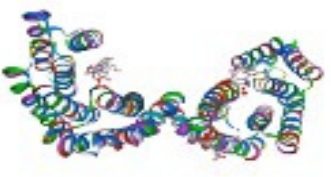

Mi14-3-3-B2

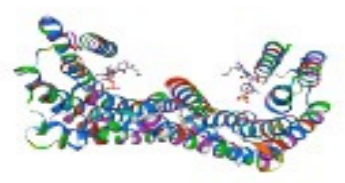

Mi14-3-3-D2

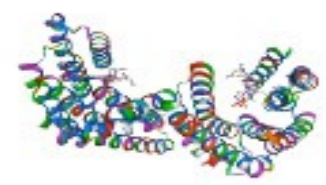

Mi14-3-3-I2

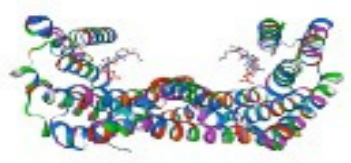

Mi14-3-3-7B

Figure 1. Tertiary structures of Mi14-3-3 proteins. 


\subsection{Multiple Sequence Alignment of Mi14-3-3 Proteins}

The multiple sequence alignment of the Mi14-3-3 protein family members via DNAMAN software (Figure 2) showed a high degree of similarity among them, and all of the proteins were found to have a PFAM00244 14-3-3 superfamily domain. These results show that the structures of the proteins in this family are highly conserved.
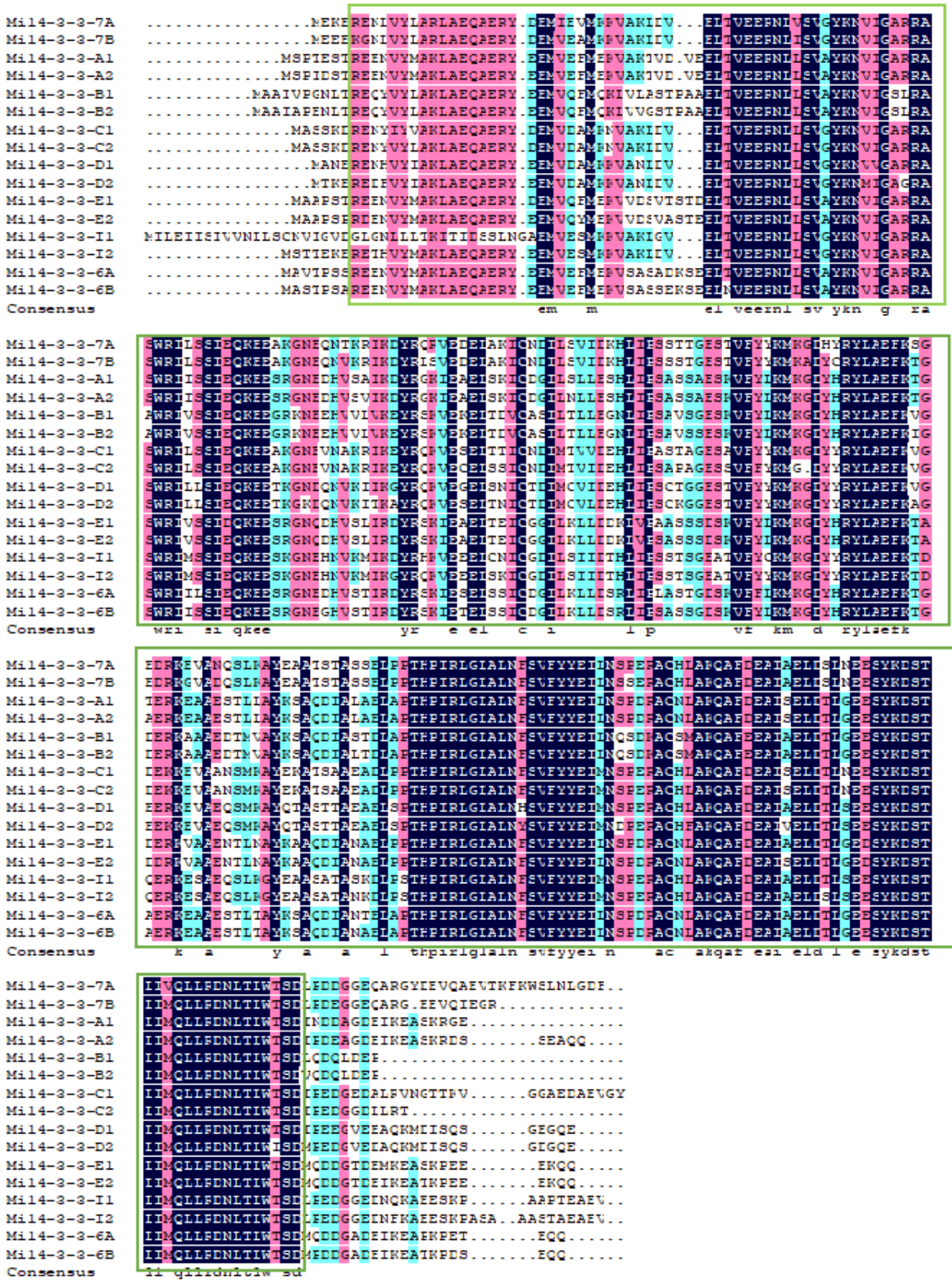

Mi14-3-3-7 Mil $4-3-3-78$ Mi14-3-3-A Mi14-3-3-E Consensus Mi14-3-3-Bi Mi14-3-3-I

Mi14-3-3-7A Mi14-3-3-7B Mi14-3-3-A Mil4-3-3-D Mi14-3-3-E Mi 14-3-3-6 Consensus

Figure 2. Multiple sequence alignment of all 14-3-3 proteins in mango. The typical conserved PFAM00244 domain is marked by a green box. 


\subsection{Gene structure and Motif Analysis}

To systematically analyse the gene structures of Mi14-3-3 genes, a 14-3-3 gene structure map (Figure 3A,B) was constructed with TBtools. Exon/intron pattern differences play crucial roles in evolution. We analysed the exon/intron maps of the Mi14-3-3 genes and found that they contained 3-5 introns. The non- $\varepsilon$ class Mi14-3-3 gene contained 3 introns, while the $\varepsilon$ class genes contained $4-5$ introns. The exon/intron patterns of the Mi14-3-3 genes were significantly different between the two groups, reflecting the diversity of Mi14-3-3 genes that has arisen during evolution (Figure 3A, Table 1). A total of 10 conserved motifs of Mi14-3-3 gene family proteins were predicted by MEME, among which motif 5 , motif 2 , motif 9 , motif 4 , motif 3 , motif 1 , and motif 6 were conserved in $\varepsilon$ class and non- $\varepsilon$ class Mi14-3-3 genes and were the characteristic motifs of Mi14-3-3s. The C-terminal motif, which may be responsible for the different target proteins, had high variability among the members of the two subfamilies; $\varepsilon$ class $14-3-3$ genes mainly contained a specific motif 10 domain, while the non- $\varepsilon$ class genes contained specific motif 8 and motif 7 domains (Figure 3C).

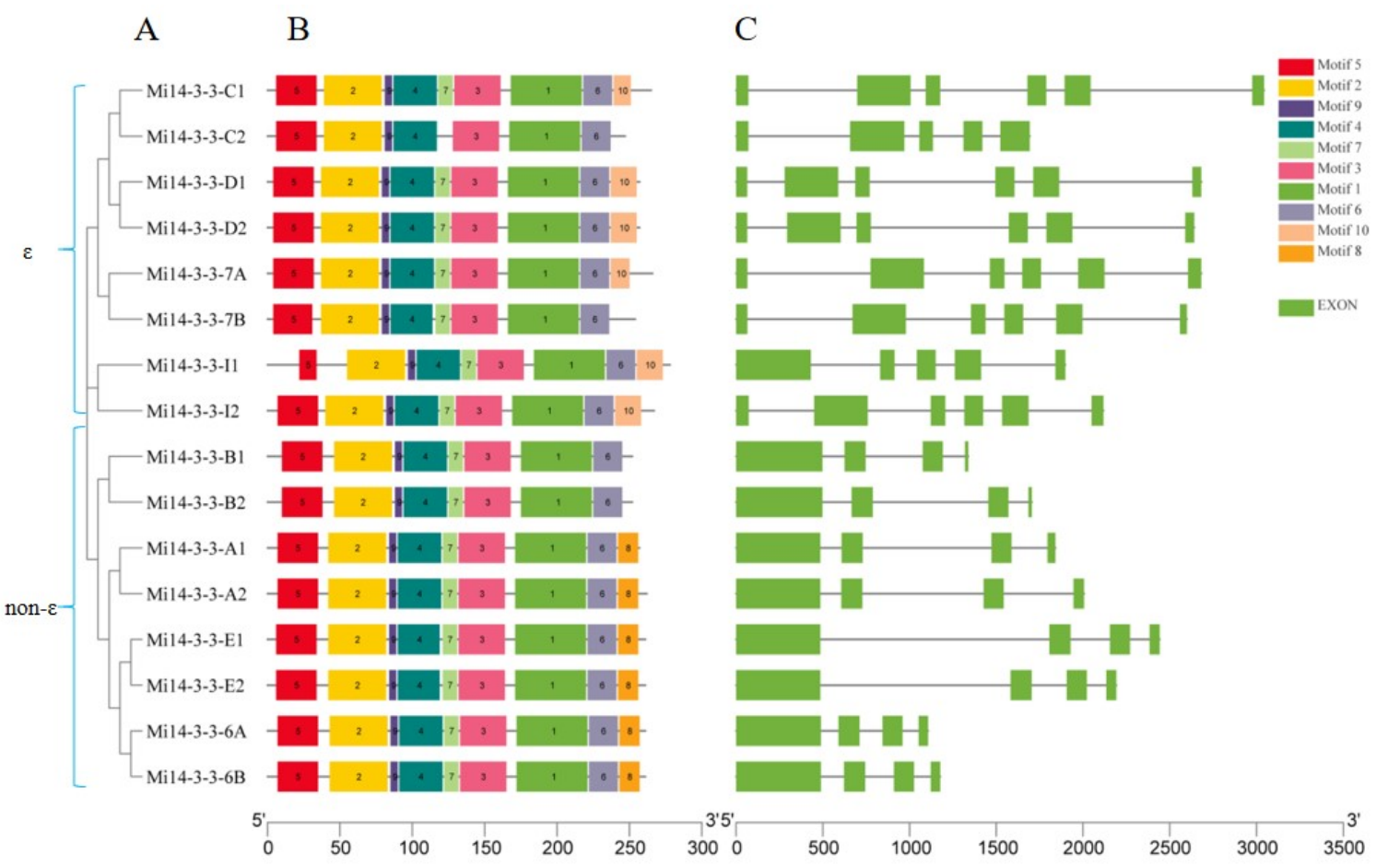

Figure 3. Phylogenetic relationships, gene structure and conserved motifs of the Mi14-3-3 genes. (A) Construction of a rootless neighbour-joining phylogenetic tree comprising 16 Mi14-3-3 gene sequences. (B) Distribution of conserved motifs within the 14-3-3 gene sequences. The differently coloured boxes represent different bases, and the motif numbers of the genes are shown in the coloured boxes. (C) Exon/intron structures of Mi14-3-3 genes. The green boxes represent exons, and the same-length black lines represent introns. The lengths of the exons can be inferred from the scale at the bottom.

\subsection{Chromosome Distribution of 14-3-3 Gene Family Members in Mango}

The positions of the 14-3-3 gene family members in the mango genome were analysed. The results showed that the 16 Mi14-3-3 genes were heterogeneously distributed on 11 of the 20 chromosomes (Figure 4). They were most densely distributed on chromosomes 10 and 18 , which had three genes each, while there were two genes on the second chromosome, and there was one on each of the other eight chromosomes. To better understand the evolution of the Mi14-3-3 genes, we examined the genome duplication events of this gene 
family. The Mi14-3-3 gene pairs presented eight sets of repeat events, but no tandem repeats.

Chromosomes 10 and 18 had the most repeat events.

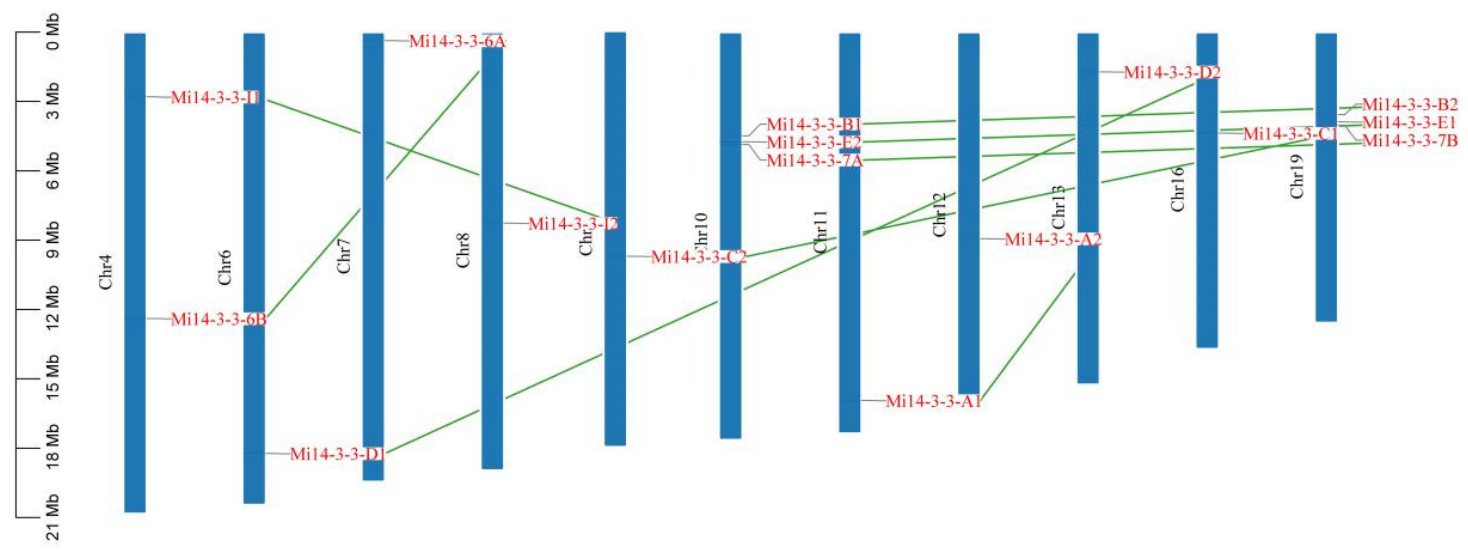

Figure 4. Genomic distribution of 14-3-3 (Mi14-3-3) genes across the eleven mango chromosomes. The list of organisms by chromosome count is shown on the upper-left side of each chromosome. The scale is in megabases $(\mathrm{Mb})$. The chromosomal locations of the Mi14-3-3s were determined according to the physical location of each gene.

\subsection{Phylogenetic Analysis of the Mi14-3-3 Genes}

To explore the evolutionary relationships of the Mi14-3-3 proteins, Arabidopsis thaliana 14-3-3 (AtGRF), Oryza sativa 14-3-3 (OsGF) and Malus domestica 14-3-3 (MdGF) genes were selected, and phylogenetic trees of mango, apple, rice and Arabidopsis 14-3-3 genes were constructed. As shown in Figure 5, the Mi14-3-3 genes were found to be very weakly related to the Arabidopsis 14-3-3 genes and were located on different branches. However, the Mi14-3-3 genes were more closely related to the apple 14-3-3 genes, suggesting that 14-3-3 genes have been more conserved during the evolution of woody plant species than in the evolution of herbaceous plant species. Similar to the Arabidopsis and rice 14-3-3 gene families, the Mi14-3-3 gene family could be divided into $\varepsilon$ class and non- $\varepsilon$ class types.

A

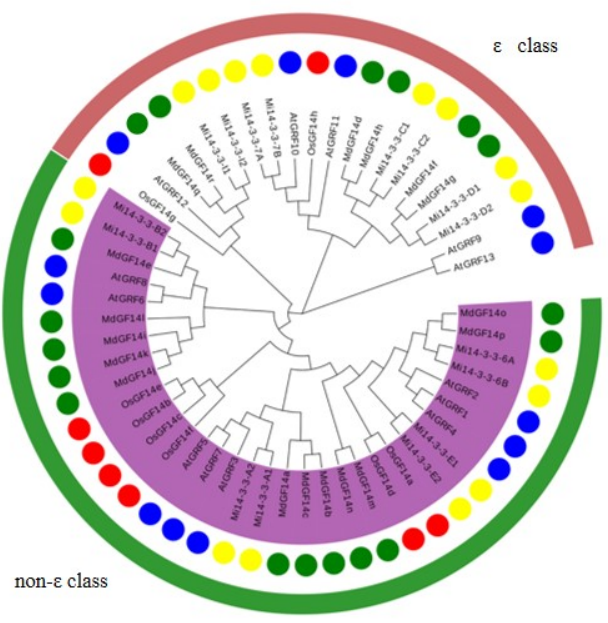

B

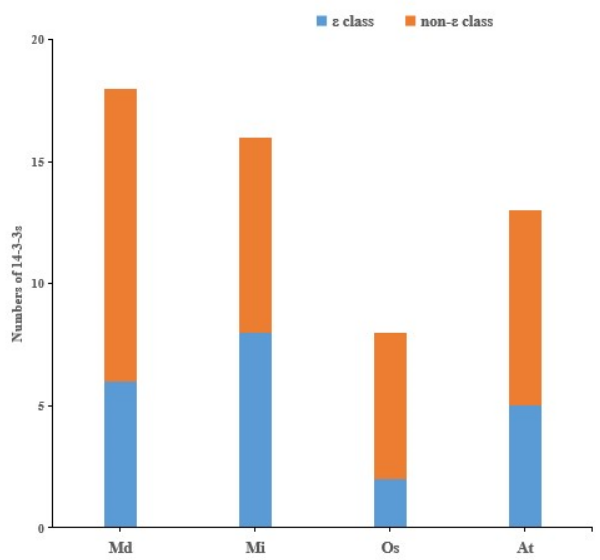

Figure 5. Phylogenetic analysis of 14-3-3 genes in Mangifera indica L., Arabidopsis thaliana, Oryza sativa, and Malus domestica. (A) The phylogenetic tree depicts the relationships among 16 Mi14-3-3 (yellow circles), 8 OsGF14 (red circles), 18 MdGF14 (green circles) and 13 AtGRF (blue circles) genes. The rootless tree was constructed using the LG model of MEGA 11.0 and divided into two subfamilies. The different groups are marked with differently coloured branches, and the different background colours indicate the various 14-3-3 gene types. (B) Statistical analysis results for 14-3-3 members from apple (Md), mango (Mi), rice (Os) and Arabidopsis (At). 


\subsection{Analysis of the Cis-Regulatory Elements of Mi14-3-3 Gene Family Member Promoters}

To understand the expression and regulatory characteristics of the Mi14-3-3 gene family members, we analysed the promoter sequence of each of these genes (the $2 \mathrm{~kb}$ region upstream of the coding region) via the PlantCARE database (Figure 6). The 16 Mi14-3-3 promoter sequences contained 21 types of photoresponsive elements, suggesting that Mi14-3-3 genes may be induced by many hormones and may participate in many plant physiological and metabolic processes. Most Mi14-3-3 promoter regions contained a variety of stress-responsive elements, including LTR-, MYB-, ARE-, MBS- and TC-rich repeats. These results indicate that members of the Mi14-3-3 family are regulated by multiple stress signals and may participate in specific growth/development, maturation/senescence, and stress-response pathways.

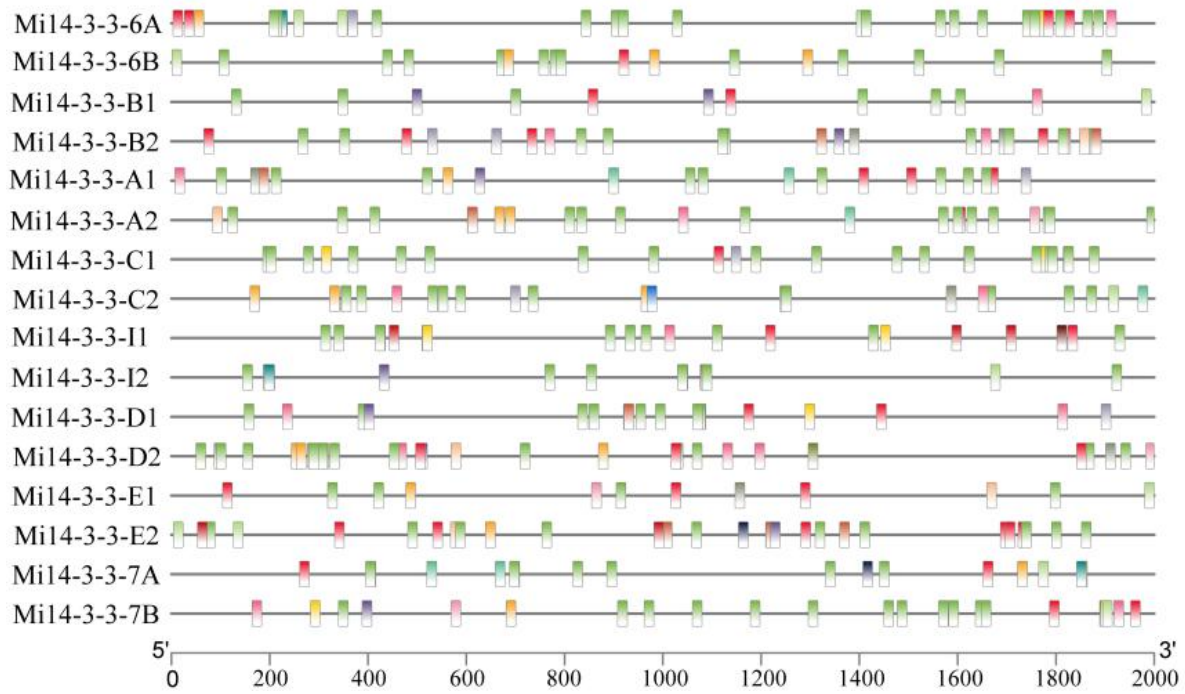

\begin{tabular}{|l}
\hline light responsive \\
MYB \\
gibberellin-responsiveness \\
cell cycle regulation \\
the anaerobic induction \\
defense and stress responsiveness \\
auxin responsiveness \\
MeJA-responsiveness \\
drought-inducibility \\
endosperm expression \\
meristem expression \\
abscisic acid responsiveness \\
low-temperature responsiveness \\
salicylic acid responsiveness \\
the palisade mesophyll cells \\
\hline anoxic specific inducibility \\
\hline flavonoid biosynthetic genes regulation \\
\hline meristem specific activation \\
\hline circadian control
\end{tabular}

Figure 6. Visualization of the results of an analysis of cis-regulatory elements within the promoters of Mi14-3-3 gene family members.

\subsection{Synteny Analysis of Mi14-3-3 Genes}

The evolution and amplification of gene families are closely related to the occurrence of tandem repeats and segmental repeats. Tandem duplication usually refers to a gene cluster formed by multiple members of a family in the same intergenic region. The most common segmental duplication event in plants leads to additional family members on different chromosomes [27]. To understand the amplification pattern of the Mi14-3-3 genes in the mango genome, we performed a collinearity analysis. The results showed that six Mi14-3-3 genes (Mi14-3-3-B1, Mi14-3-3-B2, Mi14-3-3-E1, Mi14-3-3-E2, Mi14-3-3-7A, and Mi14-3-3-7B) were linked to form two tandem repeats on chromosomes 10 and 18. The Mi14-3-3-6A/6B, Mi14-3-3-C1/C2, Mi14-3-3-D1/D2 and Mi14-3-3-I1/I2 gene pairs may have been generated by fragment duplication because they were located on different homologous chromosomes (Figure 7), and the Mi14-3-3 genes may have evolved from the copying of these genes. In addition, 11, 7 and 14 orthologous duplicated gene pairs were found between mango and Arabidopsis, Citrus sinensis and apple (Figure 7), respectively. In Figure 7, two genes connected by a line are defined as homologues; single chromosomes from the two genomes are mostly joined by lines of the same colour, indicating evolutionary similarities between those genomes. Most of the 14-3-3 genes were conserved during polyploidy, indicating their evolutionary importance. Therefore, a homology analysis provided a new way to study the evolutionary characteristics of Mi14-3-3 genes. 


\subsection{Expression Profiles of Mi14-3-3 Genes in Different Tissues}

The expression patterns of the 16 14-3-3 genes in different tissues and organs of mango were analysed. The results showed that the expression patterns of the 14-3-3 gene family members were different in different tissues (Figure 8). Mi14-3-3-E1 was expressed in most mango tissues, and Mi14-3-3-E1 was expressed in growing tissue. Mi14-3-3-I1 was highly expressed in the buds and flowers, which suggests that Mi14-3-3-I1 might play an important role in the flowering and development of mango. Mi14-3-3-A2 and Mi14-3-3-D2 were expressed mostly in young leaves. Mi14-3-3-6B and Mi14-3-3-I2 were expressed mostly in buds, and their expression was very low in the other tissues, suggesting that these two genes might play specific roles in flower bud development.

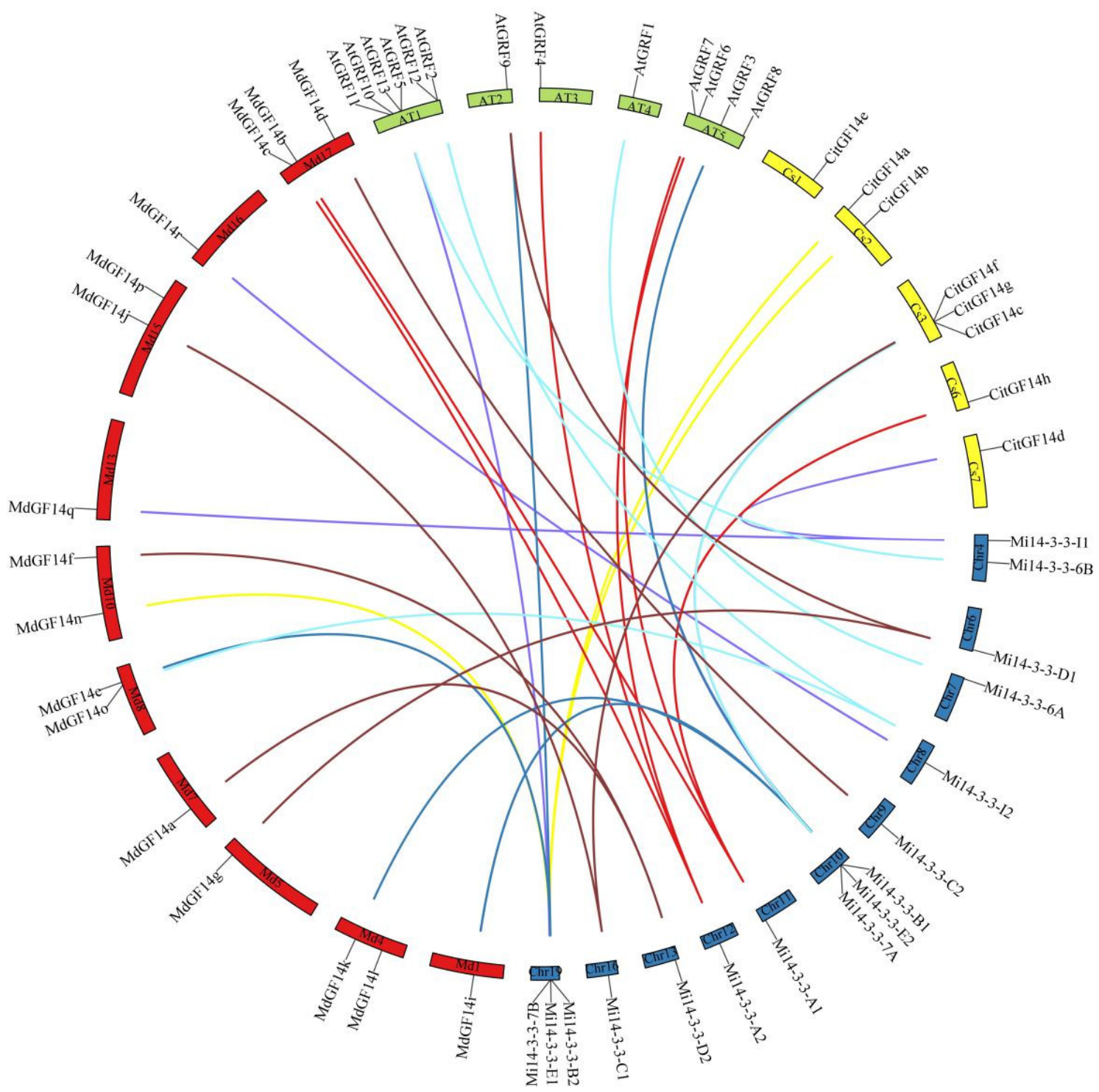

Figure 7. Syntenic relationships of mango, apple, Citrus sinensis and Arabidopsis 14-3-3 genes. The coloured curves represent mango (blue), apple (red), Citrus sinensis (yellow) and Arabidopsis (green) syntenic gene regions. The graph was generated via Circos.

\subsection{Expression Patterns of Mi14-3-3s under Abiotic Stress}

Drought, soil salinization and low temperature are the main natural factors affecting mango yield. Therefore, we used low temperature $\left(2{ }^{\circ} \mathrm{C}\right)$ stress, $30 \%$ polyethylene glycol 6000 (PEG6000)-simulated drought stress and $300 \mathrm{mM}$ salt stress to further explore the 
expression patterns of Mi14-3-3s under abiotic stress via quantitative real-time PCR (qRTPCR). We found that different Mi14-3-3 gene pairs had different expression patterns under abiotic stress. The expression patterns of the Mi14-3-3-E1/E2, Mi14-3-3-7B/B1, and Mi143-3-6A genes were upregulated at all time points during cold treatment (Figure 9A). The expression levels of four genes, Mi14-3-3-A1, Mi14-3-3-6B, Mi14-3-3-I1, and Mi14-3-3-I2, showed dynamic changes during cold treatment, while the expression levels of Mi14-3-3D1/D2 and Mi14-3-3-C1/C2 did not change significantly after cold treatment. In contrast, Mi14-3-3-B2 and Mi14-3-3-7A/A2 were significantly downregulated under cold treatment. Under drought stress, the expression of Mi14-3-3-6B/B2, Mi14-3-3-6A/A1, and Mi14-3-3-I2 increased significantly at $12 \mathrm{~h}$ and then decreased (Figure 9B). The expression levels of seven genes (Mi14-3-3-A2, Mi14-3-3-7A, Mi14-3-3-C1, Mi14-3-3-C2, Mi14-3-3-D1, Mi14-3-3$D 2$, and Mi14-3-3-I1) were generally downregulated at one time point. Five of the sixteen Mi14-3-3 genes (Mi14-3-3-7A, Mi14-3-3-A2, Mi14-3-3-D1, Mi14-3-3-E1, and Mi14-3-3-I1) were expressed in the same way; their expression increased first and then decreased under salt stress (Figure 9B). The expression of 11 genes (Mi14-3-3-6A, Mi14-3-3-A1, Mi14-3-3-6B, Mi14-3-3-7B, Mi14-3-3-B1, Mi14-3-3-B2, Mi14-3-3-C1, Mi14-3-3-C2, Mi14-3-3-D2, Mi14-33-E2, and Mi14-3-3-I2) did not change significantly under salt stress, but the expression of Mi14-3-3-6A/6B/7B/B1/B2, Mi14-3-3-A1, Mi14-3-3-D2, Mi14-3-3-E2, Mi14-3-3-C1/C2, and Mi14-3-3-I2 decreased with time.

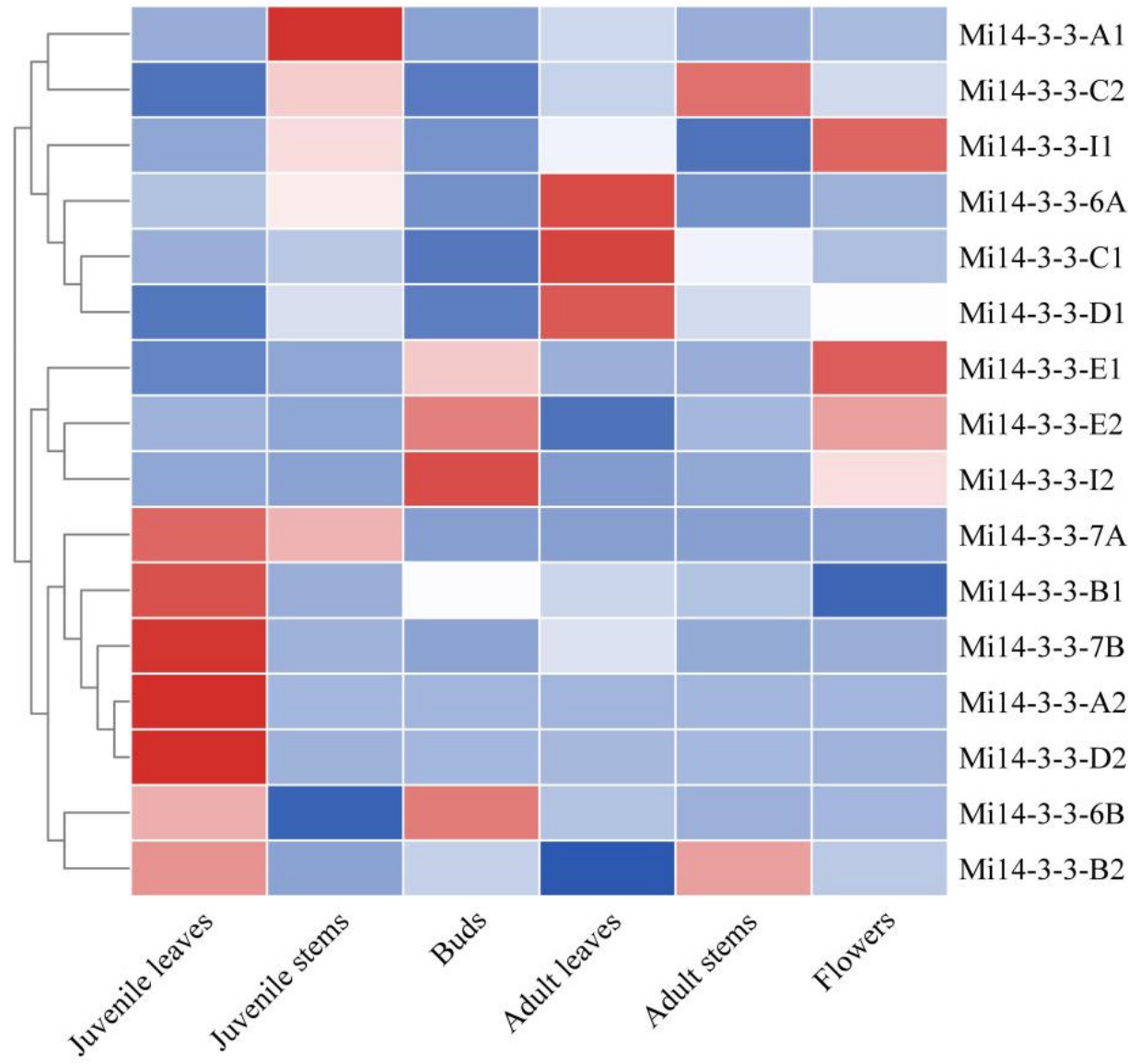

Figure 8. Expression analysis of Mi14-3-3s in different tissues and organs of mango plants. Shown is a heatmap generated by TBtools showing a cluster map of the Mi14-3-3 genes in different tissues. The colour gradient (red/white/blue) indicates the gene expression level (from high to low). 
a

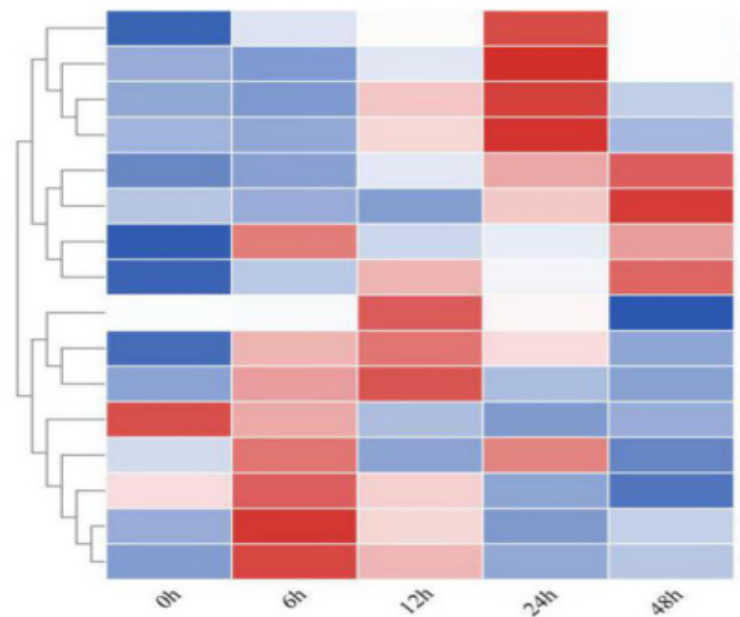

b

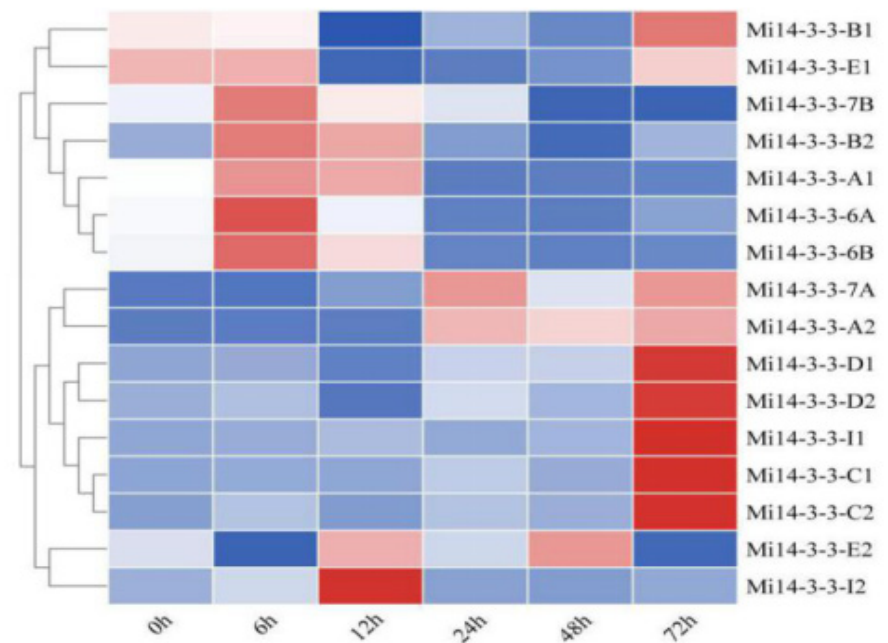

c

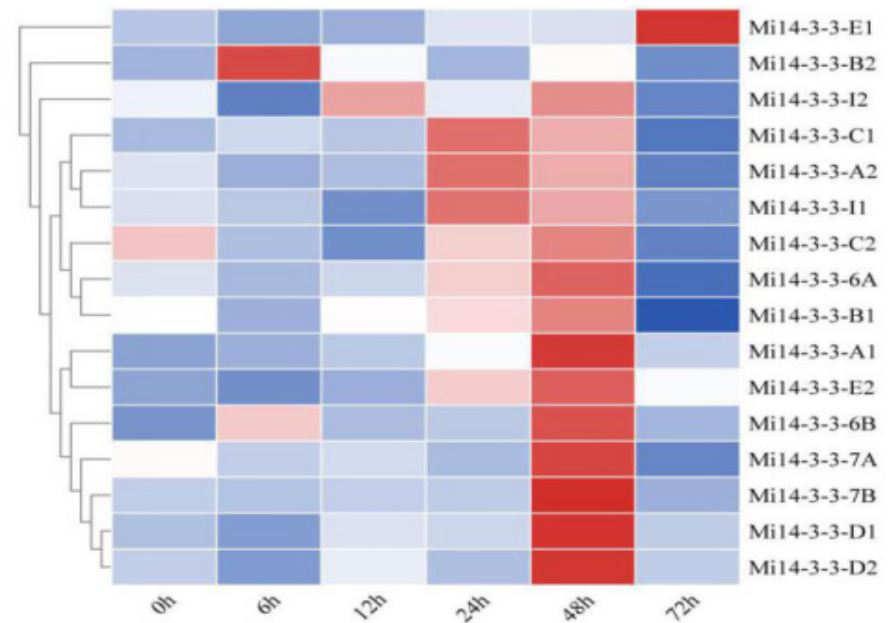

Mi14-3-3-6A

Mi 14-3-3-I1

Mi 14-3-3-C1

Mi14-3-3-C2

Mi14-3-3-E

Mi14-3-3-12

Mi14-3-3-D2

Mi14-3-3-E2

Mi14-3-3-A2

Mi14-3-3-A1

Mi14-3-3-D1

Mi14-3-3-B2

Mi 14-3-3-6B

Mil4-3-3-7A

Mi 14-3-3-7B

Mi14-3-3-B1

Mi14-3-3-B1

Mi14-3-3-B?

Mi14-3-3-AI

Mi 14-3-3-7A

Mi14-3-3-D

Mi14-3-3-I1

14-3-3-C

|i 14-3-3-E

Mil 4-3-3-A2

ii 4-3-3-I

Mi14-3-3-C2

Mi14-3-3-7B

14-3-3-D
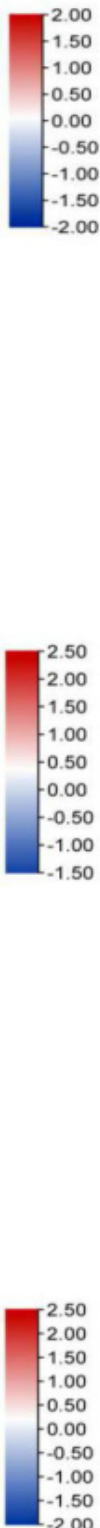

2.50
-2.00

1.50

0.00

$-1.00$

$-1.50$

Figure 9. Expression profiles of Mi14-3-3s in response to different stresses. (A) Cold stress $\left(2{ }^{\circ} \mathrm{C}\right)$ (B) Treatment with 30\% PEG6000, simulating drought stress. (C). $\mathrm{NaCl}$ (300 mM) treatment. The relative expression was normalized to that of the ACTIN gene, used as a reference, via the $2^{-\Delta \Delta \mathrm{Ct}}$ method. The heatmaps were generated based on the log2 (treatment expression/control expression) values with HemI. The colour gradient (red/white/blue) indicates the gene expression level (from high to low). The values indicate the means of three biological replications.

\section{Discussion}

As regulatory factors involved in plant hormone signal transduction and metabolism, 14-3-3 proteins play important roles in plant growth, development and stress responses. 
Using a bioinformatic method, we identified 16 members of the 14-3-3 gene family in mango. In marked contrast to the findings of previous studies on Arabidopsis thaliana [19], rice [20] and apple [24], the Mi14-3-3 family genes were not evenly distributed across chromosomes. The analysis of the physicochemical properties of the Mi14-3-3 proteins showed that the proteins were acidic and thus stable, similar to apple 14-3-3 proteins. The secondary structures of Mi14-3-3 proteins were similar to those of Arabidopsis and apple 14-3-3 proteins. In addition, the three-dimensional structures of Mi14-3-3 family proteins were very similar to those of Arabidopsis 14-3-3 family proteins, and the Mi14-3-3 gene family members could be classified into $\varepsilon$ and non- $\varepsilon$ classes according to their phylogenetic relationships. The Mi14-3-3 proteins were most closely related to apple 14-3-3 proteins, which is consistent with the fact that mango and apple are woody plant species. A genetic structure analysis showed that $\varepsilon$ class Mi14-3-3 genes contained more exons and introns than the non- $\varepsilon$ class Mi14-3-3 genes did, suggesting that evolution drove this diversity. In other species, the non- $\varepsilon$ class $14-3-3$ proteins are more abundant than the $\varepsilon$ class $14-3-3$ proteins, while in mango, the numbers of 14-3-3 proteins were the same. Conserved motif analysis showed that there were seven conserved motifs in the $\varepsilon$ class and non- $\varepsilon$ class Mi143 -3s. The C-terminal motifs were highly variable; these motifs directly affect the interactions between 14-3-3 proteins and other proteins. The diverse motifs in the Mi14-3-3 gene family are the core 14-3-3 protein structures that bind to many ligands [28]. Gene families evolve from tandem and fragmented duplication of genes. Through a homology analysis, tandem and fragment repeats were found in Mi14-3-3 genes, indicating the possibility of horizontal duplication within the Mi14-3-3 gene family [29].

The promoters of the Mi14-3-3 genes were found to contain several light-responsive cis-regulatory elements, which implies that the Mi14-3-3 genes are induced by light signals and participate in a complex light signal response. In Arabidopsis thaliana, 14-3-3 protein 1 (Phot1) is specifically bound under blue light [30], and under red light, At14-3-3 $\mu$ and At14-3-3 $v$ interact with photoperiod regulatory proteins [31]. The Mi14-3-3 gene promoters contained several cis-regulatory elements that respond to abscisic acid (ABA), GA, auxin and other signals. Studies on barley Hv14-3-3 have shown that 14-3-3 proteins are induced by ABA signalling and participate in ABA signalling [32]. By regulating the subcellular location of REPRESSION OF SHOOT GROWTH (RSG) transcription factors, tobacco 14-3-3 proteins negatively regulate GA expression [33]. In Arabidopsis, 14-3-3 proteins can also maintain ethylene levels by increasing the stability of 1-aminocyclopropane-1carboxylate synthase (ACS) proteins and reducing E3 ubiquitin ligase binding [34]. In addition, Arabidopsis $\varepsilon$ class 14-3-3 proteins affect the polarity-regulated indole-acetic acid (IAA) concentration gradient of the PIN-FORMED auxin efflux protein on the plasma membrane, thereby participating in the plant development process regulated by IAA [35].

The expression pattern of Mi14-3-3-E1 was different in different tissues. Mi14-3-3-7A was expressed mostly in the stems and leaves, Mi14-3-3-I1 was expressed mostly in the flower buds and flowers, and Mi14-3-3-6B and Mi14-3-3-I2 were expressed only in the flower buds.

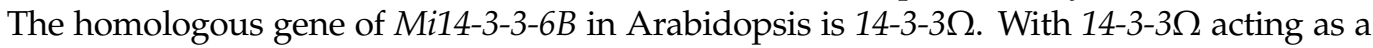
universal regulator, SUPPRESSOR OF OVEREXPRESSION OF CONSTANS1 (SOC1) regulates the flower-forming factors $F T$ and $F D$, which induce the accumulation of the oxidative stress factor Oxs2 and the expression of the flower-forming factor $F T$, both of which are involved in early flowering in Arabidopsis. The accumulation of Oxs 2 in the cytoplasm inhibits FT entry into the nucleus and inhibits early flowering in Arabidopsis [36]. In the GA pathway, the $b$ ZIP transcription factor RSG, which is a key enzyme involved in GA synthesis in plants, has been shown to interact with 14-3-3s via yeast two-hybrid screening. In tobacco and Arabidopsis, GA promotes plant flowering. 14-3-3 proteins have been shown to bind to RSGs phosphorylated by NTCDPK1, preventing those RSGs from entering the nucleus and thus negatively regulating endogenous GA synthesis-related signalling [33,37,38].

Cold stress decreased the transcript levels of Mi14-3-3s in the leaves, and two of the promoters contained LTRs. Arabidopsis RCI1A (AtGRF3) upregulates ethylene synthesis and inhibits ethylene-dependent cold tolerance-related gene expression under cold stress [9]. 
The AtGRF3 homologous gene Mi14-3-3-A2 in mango was downregulated under cold stress, which suggests that Mi14-3-3-A2 might be a positive regulator of cold stress. Under normal growth conditions or drought stress conditions, OsGF14B can alter the levels of stress-related parameters and the expression of stress-related genes. Through ABA signalling, OsGF14B participates in and negatively regulates both the drought and the osmotic resistance of rice plants [39]. The expression of Mi14-3-3-A1, a homologous gene of AtGRF7 in Arabidopsis thaliana, was initially upregulated during drought treatment, but it was downregulated after $12 \mathrm{~h}$ of drought treatment. The expression of the Mi14-3-3-A1 homolog AtGRF7 in Arabidopsis thaliana has been found to be increased in a mutant in which AtGRF7 was silenced [10]; however, the expression of Mi14-3-3-A1 in the current study decreased after $12 \mathrm{~h}$ of drought treatment. Under salt stress, the GhGRF3, GhGRF4, GhGRF5, GhGRF7 and GhGRF16 genes have been found to be downregulated in the leaves of cotton [18], and GhN/AINV13 has been shown to interact with 14-3-3 proteins to improve resistance to stresses, such as salt stress in upland cotton [40]. In the present study, five 14-3-3 genes, Mi14-3-3-7A, Mi14-3-3-A2, Mi14-3-3-D1, Mi14-3-3-E1, and Mi14-3-3-I1, were upregulated or downregulated after salt treatment, which indicates that Mi14-3-3 genes are controlled by different regulatory mechanisms under stress. Under drought stress, overexpression of 14-3GF (which encodes a 14-3-3 protein) in maize promotes maize symbiosis and resistance to stress from arbuscular mycorrhizae [41]. Gene expression analysis has shown that ZmGF14- 6 of maize (which encodes a 14-3-3 protein) is upregulated in response to fungal infection and salt treatment, but it is downregulated in response to drought stress [42]. Moreover, the drought tolerance of Arabidopsis thaliana mutant progeny is improved by silencing the 14-3-3 protein-encoding gene AtGF14m [10]. In transgenic SiGRF1-overexpressing plants under high-salinity conditions, the gene expression levels of the flowering genes FT and LEAFY (LFY) increase, resulting in early flowering [43]. In addition, the expression levels of the 14-3-3 protein-encoding gene MdGRF11 in apple increase significantly under salt stress and low temperature stress [44].

\section{Materials and Methods}

\subsection{Materials and Treatments}

The information on the Mi14-3-3 gene family in this study was based on the sequenced variety 'Sijimi', which flowers more than once a year. This variety was developed by researchers at Guangxi University and has high breeding and scientific research value. In this experiment, mango plants with mature and stable characteristics were cultivated in the experimental garden of Guangxi University; the flowering habits of these plants contrast with the flowering habits of annuals and other woody plant species. Tissue and organ samples of mango were collected from mature leaves, mature stems, and flowers of mature trees, while leaves, stems, and buds were collected from young trees. For the abiotic stress experiments, 10-year-old Mangifera indica plants were used as samples. These trees were subjected to low temperature $\left(2{ }^{\circ} \mathrm{C}\right)$ stress, 30\% PEG6000-simulated drought stress and $300 \mathrm{mM}$ salt stress. Samples were collected before and after $6 \mathrm{~h}, 12 \mathrm{~h}, 24 \mathrm{~h}, 48 \mathrm{~h}$ and $72 \mathrm{~h}$ of treatment. The samples were immediately frozen and stored at $-80{ }^{\circ} \mathrm{C}$ until use.

\subsection{Identification and Sequence Analysis of 14-3-3 Gene Family Members in Mango}

To identify potential 14-3-3 gene family members in the mango genome, the 'SiJiMi' mango genome (unpublished) was used. The sequences of 15 members of the 14-33 family were obtained from the Arabidopsis thaliana genome database [45] and were used as query sequences to search for sequences of Mi14-3-3 homologous genes in the mango genome database via local BLAST searches. After screening according to an e value $<1 \times 10^{-10}$ and an identity $>40 \%$, we used the Pfam [46] (https:/ / pfam.janelia. org, accessed on 6 January 2021) and SMART [47] (http: / /SMART.emblheidelberg.de, accessed on 2 March 2021) online tools to identify the domains of the retrieved Mi143-3 protein sequences and eliminate the proteins with missing domains. Finally, the candidate genes of the Mi14-3-3 family were obtained. In addition, the online ExPASy 
program (http://www.ExPASy.org/tools, accessed on 12 March 2021) was used to predict the three parameters (length, MW and pI) of each 14-3-3 protein [48]. The amino acid number, MW and theoretical $\mathrm{pI}$ of each Mi14-3-3 protein were predicted by ProtParam [49]. The subcellular localization of each member was predicted using the subcellular localization prediction tool WoLF PSORT (https://wolfpsort.hgc.jp, accessed on 20 March 2021), and SWISS-MODEL (https: / / swissmodel.expasy.org, accessed on 14 March 2021) was used to construct homologous models of the proteins and obtain models of their three-dimensional structures.

\subsection{Chromosomal Location and Gene Structure Analyses}

The chromosomal locations of the Mi14-3-3 gene family members were extracted from the gff3 file of the mango genome annotation, and a map of the chromosomal gene distribution was constructed with MapChart software [50]. Using the Gene Structure Display Server (GSDS) [51] online tool (http:/ /GSDS.cbi.pku.edu.cn, accessed on 3 April 2021), we predicted the numbers of exons and introns, and the 14-3-3 gene structures were determined. The conserved amino acid sequences of the proteins were analysed online via MEME software (http:/ /MEME-suite.org, accessed on 5 April 2021); the number of motifs was set to 10, and the other parameters were set to their default values [52]. The motif structures were drawn with TBtools [53].

\subsection{Sequence Alignment and Phylogenetic Analyses}

The amino acid conservation of the protein sequences was analysed with DNAMANx software. The amino acid sequences of Arabidopsis, rice and apple 14-3-3 proteins were downloaded from the Arabidopsis, rice and apple genome databases, respectively, and the online tool CLUSTAL OMEGA (https:/ / www.ebi.ac.uk/Tools/msa/clustalo, accessed on 9 April 2021) was used for multiple sequence alignment of the 14-3-3 proteins of the three plant species [54]. A phylogenetic tree was constructed by the adjacency method in MEGA 11.0 (bootstrap number set to 1000) [55].

\subsection{Prediction of Cis-Regulatory Elements}

The sequence of the $2 \mathrm{~kb}$ region upstream of the start codon of each Mi14-3-3 gene was extracted from the gff 3 file of the mango genome annotation and considered the promoter sequence [56]. Predictions of cis-regulatory elements within the promoter were then made via the PlantCARE database (http://bioinformatics.psb.ugent.be/webtools/plantcare/ html, accessed on 5 March 2021).

\subsection{Tandem Duplication and Synteny Analysis}

Tandem duplication and synteny relationships were analysed using Circos 0.63 (http: / / circos.ca, accessed on 18 April 2021) [57]. According to previously published papers, gene duplication events were defined by their chromosomal locations: genes on the same chromosome were considered tandem repeat genes, and genes located on different chromosomes were considered segmental repeat genes [58,59]. A homology analysis of apple, Arabidopsis thaliana and citrus was carried out using a plant genome replication database (http:/ / chibba.agtec.uga.edu/duplication, accessed on 11 May 2021), and TBtools was used to display linked pairs [53].

\subsection{RNA Extraction and $q R T-P C R$}

An improved nucleic acid extraction method was used to extract RNA from mango. The mango RNA was extracted with an Easy Pure ${ }^{\circledR}$ Plant RNA Kit (TransGen Biotech, Beijing, China). Reverse transcription was performed using the reverse transcription enzyme PrimeScript ${ }^{\mathrm{TM}}$ Reverse Transcriptase II (Takara) according to the manufacturer's instructions. The cDNA was then concentrated spectrophotometrically to $50 \mathrm{ng} / \mathrm{L}$. Based on the sequence information of the 14-3-3 genes and the mango internal reference gene MiACT1, primers for each gene were designed with Primer 3 Plus online software. qRT-PCR was 
performed with an ABI7500 instrument (Applied Biosystems, Foster, USA) according to the manufacturer's instructions. Each sample was divided into 3 replicates. The data were processed by the $2^{-\Delta \Delta C T}$ method [60], and a heatmap of the gene expression profile was constructed with TBtools software [53].

\section{Conclusions}

In summary, mango 14-3-3 genes are largely involved in plant development and stress responses, but the roles of the different members in stress responses and in signal transduction need to be further studied. In this study, 16 members of the Mi14-3-3 gene family were identified by bioinformatic analysis, and the results of evolutionary analysis revealed that the mango 14-3-3 genes have undergone duplication and loss throughout evolution. Taken together, the results show that the members of the Mi14-3-3 gene family might be involved in plant growth, development, stress responses and other physiological and biochemical processes; therefore, further study of the function and regulation of mango 14-3-3 family members is very important.

Supplementary Materials: The following are available online at https:/ /www.mdpi.com/article/10 .3390/ijms23031593/s1.

Author Contributions: X.H. and C.L. designed and financed this experiment. L.X. and X.H. (Xing Huang) performed the experiments. H.Y., T.L., X.X., X.Z. and J.Z. helped with the experiments and data analysis. L.X. and X.H. (Xinhua He) wrote the manuscript. All authors have read and agreed to the published version of the manuscript.

Funding: This research was supported by the National Natural Science Foundation of China: 31860541; Innovation Team of Guangxi Mango Industry Project: nycytxgxcxtd-2021-06-02; Guangxi Science and Technology Vanguard Special Action Project: 202104; State Key Laboratory for Conservation and Utilization of Subtropical Agro-bioresources: SKLCUSA-a201906, SKLCUSA-c201901; and Innovation Project of Guangxi Graduate Education (YCSW2021043).

Institutional Review Board statement: Not applicable.

Informed consent statement: Not applicable.

Data availability statement: Not applicable.

Conflicts of Interest: The authors declare that they have no conflicts of interest.

\section{References}

1. Camoni, L.; Visconti, S.; Aducci, P.; Marra, M. 14-3-3 proteins in Plant Hormone Signaling: Doing Several Things at Once. Front. Plant Sci. 2018, 9, 297. [CrossRef] [PubMed]

2. Pnueli, L.; Gutfinger, T.; Hareven, D.; Ben-Naim, O.; Ron, N.; Adir, N.; Lifschitz, E. Tomato SP-interacting proteins define a conserved signaling system that regulates shoot architecture and flowering. Plant Cell 2001, 13, 2687-2702. [CrossRef] [PubMed]

3. Li, B.; Xiao, G.; Luo, K.; Wang, Z.; Mao, B.; Lin, X.; Guo, X. Overexpression of PvGF14c from Phyllostachys violascens Delays Flowering Time in Transgenic Arabidopsis. Front. Plant Sci. 2018, 9, 105. [CrossRef] [PubMed]

4. Mayfield, J.D.; Folta, K.M.; Pau, A.L.; Ferl, R.J. The 14-3-3 proteins mu and upsilon influence transition to flowering and early phytochrome response. Plant Physiol. 2007, 145, 1692-1702. [CrossRef] [PubMed]

5. Kaneko-Suzuki, M.; Kurihara-Ishikawa, R.; Okushita-Terakawa, C.; Kojima, C.; Nagano-Fujiwara, M.; Ohki, I.; Tsuji, H.; Shimamoto, K.; Taoka, K.I. TFL1-Like Proteins in Rice Antagonize Rice FT-Like Protein in Inflorescence Development by Competition for Complex Formation with 14-3-3 and FD. Plant Cell Physiol. 2018, 59, 458-468. [CrossRef]

6. Schoonheim, P.J.; Costa Pereira, D.D.; De Boer, A.H. Dual role for 14-3-3 proteins and ABF transcription factors in gibberellic acid and abscisic acid signalling in barley (Hordeum vulgare) aleurone cells. Plant Cell Environ. 2009, 32, 439-447. [CrossRef]

7. Xu, W.; Jia, L.; Shi, W.; Baluska, F.; Kronzucker, H.J.; Liang, J.; Zhang, J. The Tomato 14-3-3 protein TFT4 modulates H+ efflux, basipetal auxin transport, and the PKS5-J3 pathway in the root growth response to alkaline stress. Plant Physiol. 2013, 163, 1817-1828. [CrossRef]

8. $\mathrm{Xu}$, W.F.; Shi, W.M. Expression profiling of the 14-3-3 gene family in response to salt stress and potassium and iron deficiencies in young tomato (Solanum lycopersicum) roots: Analysis by real-time RT-PCR. Ann. Bot. 2006, 98, 965-974. [CrossRef]

9. Catalá, R.; López-Cobollo, R.; Mar-Castellano, M.; Angosto, T.; Alonso, J.M.; Ecker, J.R.; Salinas, J. The Arabidopsis 14-3-3 protein RARE COLD INDUCIBLE 1A links low-temperature response and ethylene biosynthesis to regulate freezing tolerance and cold acclimation. Plant Cell 2014, 26, 3326-3342. [CrossRef] 
10. Sun, X.; Luo, X.; Sun, M.; Chen, C.; Ding, X.; Wang, X.; Yang, S.; Yu, Q.; Jia, B.; Ji, W.; et al. A Glycine soja 14-3-3 protein GsGF14o participates in stomatal and root hair development and drought tolerance in Arabidopsis thaliana. Plant Cell Physiol. 2014, 55, 99-118. [CrossRef]

11. Chen, Y.; Zhou, X.; Chang, S.; Chu, Z.; Wang, H.; Han, S.; Wang, Y. Calcium-dependent protein kinase 21 phosphorylates 14-3-3 proteins in response to ABA signaling and salt stress in rice. Biochem. Biophys. Res. Commun. 2017, 493, 1450-1456. [CrossRef] [PubMed]

12. Mayfield, J.D.; Paul, A.L.; Ferl, R.J. The 14-3-3 proteins of Arabidopsis regulate root growth and chloroplast development as components of the photosensory system. J. Exp. Bot. 2012, 63, 3061-3070. [CrossRef] [PubMed]

13. Chen, Y.; David, H.; Tuan, H.; Liu, L.H.; Lee, D.H.; Lee, C.H.; Chen, Y.R.; Lin, S.Y.; Lu, C.A.; Yu, S.M. Sugar starvation-regulated MYBS2 and 14-3-3 protein interactions enhance plant growth, stress tolerance, and grain weight in rice. Proc. Natl. Acad. Sci. USA 2019, 116, 21925-21935. [CrossRef] [PubMed]

14. Yang, L.; You, J.; Wang, Y.; Li, J.; Quan, W.; Yin, M.; Wang, Q.; Chan, Z. Systematic analysis of the G-box Factor 14-3-3 gene family and functional characterization of GF14a in Brachypodium distachyon. Plant Physiol. Biochem. 2017, 117, 1-11. [CrossRef] [PubMed]

15. Yang, Z.P.; Li, H.L.; Guo, D.; Tang, X.; Peng, S.Q. Identification and characterization of the 14-3-3 gene family in Hevea brasiliensis. Plant Physiol. Biochem. 2014, 80, 121-127. [CrossRef]

16. Purwestri, Y.A.; Ogaki, Y.; Tamaki, S.; Tsuji, H.; Shimamoto, K. The 14-3-3 protein GF14c acts as a negative regulator of flowering in rice by interacting with the florigen Hd3a. Plant Cell Physiol. 2009, 50, 429-438. [CrossRef]

17. Taoka, K.; Ohki, I.; Tsuji, H.; Furuita, K.; Hayashi, K.; Yanase, T.; Yamaguchi, M.; Nakashima, C.; Purwestri, Y.A.; Tamaki, S.; et al. 14-3-3 proteins act as intracellular receptors for rice Hd3a florigen. Nature 2011, 476, 332-335. [CrossRef]

18. Cao, J.; Cao, J.F.; Huang, J.Q.; Liu, X.; Huang, C.C.; Zheng, Z.S.; Zhang, X.F.; Shangguan, X.X.; Wang, L.J.; Zhang, Y.G.; et al Genome-wide characterization of the GRF family and their roles in response to salt stress in Gossypium. BMC Genom. 2020, 21, 575. [CrossRef]

19. Rosenquist, M.; Alsterfjord, M.; Larsson, C.; Sommarin, M. Data Mining the Arabidopsis genome reveals fifteen 14-3-3 genes, expression is demonstrated for two out of five novel genes1. Plant Physiol. 2001, 127, 142-149. [CrossRef]

20. Chen, F.; Li, Q.; Sun, L.; He, Z. The rice 14-3-3 gene family and its involvement in responses to biotic and abiotic stress. DNA Res. 2006, 13, 53-63. [CrossRef]

21. Li, X.; Dhaubhadel, S. Soybean 14-3-3 gene family: Identification and molecular characterization. Planta 2011, $233,569-582$. [CrossRef] [PubMed]

22. Konagaya, K.; Matsushita, Y.; Kasahara, M.; Nyunoya, H. Members of 14-3-3 protein isoforms interacting with the resistance gene product $\mathrm{N}$ and the elicitor of Tobacco mosaic virus. J. Gen. Plant Pathol. 2004, 70, 221-231. [CrossRef]

23. Tian, F.; Wang, T.; Xie, Y.; Zhang, J.; Hu, J. Genome-wide identification, classification, and expression analysis of 14-3-3 gene family in Populus. PLoS ONE. 2015, 10, e0123225. [CrossRef] [PubMed]

24. Zuo, X.; Wang, S.; Xiang, W.; Yang, H.; Tahir, M.M.; Zheng, S.; An, N.; Han, M.; Zhao, C.; Zhang, D. Genome-wide identification of the 14-3-3 gene family and its participation in floral transition by interacting with TFL1/FT in apple. BMC Genom. 2021, 22, 41. [CrossRef] [PubMed]

25. Lyu, S.; Chen, G.; Pan, D.; Chen, J.; She, W. Molecular Analysis of 14-3-3 Genes in Citrus sinensis and Their Responses to Different Stresses. Int. J Mol Sci. 2021, 22, 568. [CrossRef] [PubMed]

26. Deshpande, A.B.; Anamika, K.; Jha, V.; Chidley, H.G.; Oak, P.S.; Kadoo, N.Y.; Pujari, K.H.; Giri, A.P.; Gupta, V.S. Transcriptional transitions in Alphonso mango (Mangifera indica L.) during fruit development and ripening explain its distinct aroma and shelf life characteristics. Sci. Rep. 2017, 7, 8711. [CrossRef] [PubMed]

27. Cannon, S.B.; Mitra, A.; Baumgarten, A.; Young, N.D.; May, G. The roles of segmental and tandem gene duplication in the evolution of large gene families in Arabidopsis thaliana. BMC Plant Biol. 2004, 4, 10. [CrossRef]

28. Yang, X.W.; Lee, W.H.; Sobott, F.; Papagrigoriou, E.; Robinson, C.V.; Grossmann, J.G.; Sundström, M.; Doyle, D.A.; Elkins, J.M. Structural basis for protein-protein interactions in the 14-3-3 protein family. Proc. Natl. Acad. Sci. USA 2006, 103, 17237-17242. [CrossRef]

29. Aducci, P.; Camoni, L.; Marra, M.; Visconti, S. From cytosol to organelles: 14-3-3 proteins as multifunctional regulators of plant cell. IUBMB Life 2002, 53, 49-55. [CrossRef]

30. Sullivan, S.; Thomson, C.E.; Kaiserli, E.; Christie, J.M. Interaction specificity of Arabidopsis 14-3-3 proteins with phototropin receptor kinases. FEBS Lett. 2009, 583, 2187-2193. [CrossRef]

31. Folta, K.M.; Paul, A.; Mayfield, J.D.; Ferl, R.J. 14-3-3 isoforms participate in red light signaling and photoperiodic flowering. Plant Signal. Behav. 2008, 3, 304-306. [CrossRef] [PubMed]

32. Schoonheim, P.J.; Sinnige, M.P.; Casaretto, J.A.; Veiga, H.; Bunney, T.D.; Quatrano, R.S.; De Boer, A.H. 14-3-3 adaptor proteins are intermediates in ABA signal transduction during barley seed germination. Plant J. 2007, 49, 289-301. [CrossRef] [PubMed]

33. Ishida, S.; Fukazawa, J.; Yuasa, T.; Takahashi, Y. Involvement of 14-3-3 signaling protein binding in the functional regulation of the transcriptional activator REPRESSION OF SHOOT GROWTH by gibberellins. Plant Cell 2004, 16, 2641-2651. [CrossRef] [PubMed]

34. Yoon, G.M.; Kieber, J.J. 14-3-3 regulates 1-aminocyclopropane-1-carboxylate synthase Protein turnover in Arabidopsis. Plant Cell 2013, 25, 1016-1028. [CrossRef]

35. Keicher, J.; Jaspert, N.; Weckermann, K.; Moller, C.; Throm, C.; Kintzi, A.; Oecking, C. Arabidopsis 14-3-3 epsilon members contribute to polarity of PIN auxin carrier and auxin transport-related development. eLife 2017, 6, 605. [CrossRef] 
36. Liang, M.; Ow, D.W. Nucleocytoplasmic OXIDATIVE STRESS 2 can relocate FLOWERING LOCUS T. Biochem. Biophys. Res. Commun. 2019, 517, 735-740. [CrossRef]

37. Ishida, S.; Yuasa, T.; Nakata, M.; Takahashi, Y. A tobacco calcium-dependent protein kinase, CDPK1, regulates the transcription factor REPRESSION OF SHOOT GROWTH in response to gibberellins. Plant Cell 2008, 20, 3273-3288. [CrossRef]

38. Ormancey, M.; Thuleau, P.; Mazars, C.; Cotelle, V. CDPKs and 14-3-3 proteins: Emerging Duo in Signaling. Trends Plant Sci. 2017, 22, 263-272. [CrossRef]

39. Liu, J.; Sun, X.; Liao, W.; Zhang, J.; Liang, J.; Xu, W. Involvement of OsGF14b Adaptation in the Drought Resistance of Rice Plants Rice 2019, 12, 82. [CrossRef]

40. Chen, B.Z.; Wang, X.Y.; Lv, J.Y.; Ge, M.J.; Qiao, K.K.; Chen, Q.J.; Zhang, K.P.; Wang, J.S.; Fan, S.L.; Ma, Q.F. GhN/AINV13 positively regulates cotton stress tolerance by interacting with the 14-3-3 protein. Genomics. 2021, 113, 44-56. [CrossRef]

41. He, Y.; Wu, J.; Lv, B.; Li, J.; Gao, Z.; Xu, W.; Baluška, F.; Shi, W.; Shaw, P.C.; Zhang, J. Involvement of 14-3-3 protein GRF9 in root growth and response under polyethylene glycol-induced water stress. J. Exp. Bot. 2015, 66, 2271-2281. [CrossRef] [PubMed]

42. Campo, S.; Peris-Peris, C.; Montesinos, L.; Peñas, G.; Messeguer, J.; San, S.B. Expression of the maize ZmGF14-6 gene in rice confers tolerance to drought stress while enhancing susceptibility to pathogen infection. J Exp Bot. 2012, 63, 983-999. [CrossRef] [PubMed]

43. Liu, J.M.; Jiang, C.Y.; Kang, L.; Zhang, H.C.; Song, Y.; Zou, Z.R.; Zheng, W.J. Over-Expression of a 14-3-3 protein From Foxtail Millet Improves Plant Tolerance to Salinity Stress in Arabidopsis thaliana. Front. Plant Sci. 2020, 11, 449. [CrossRef] [PubMed]

44. Ren, Y.; Yang, Y.Y.; Zhang, R.; You, C.X.; Zhao, Q.; Hao, Y.J. MdGRF11, an apple 14-3-3 protein, acts as a positive regulator of drought and salt tolerance. Plant Sci. 2019, 288, 110219. [CrossRef] [PubMed]

45. Poole, R.L. The TAIR database. Methods Mol. Biol. 2007, 406, 179-212. [PubMed]

46. Letunic, I.; Bork, P. 20 years of the SMART protein domain annotation resource. Nucleic Acids Res. 2018, 46, D493-D496. [CrossRef]

47. Finn, R.D.; Coggill, P.; Eberhardt, R.Y.; Eddy, S.R.; Mistry, J.; Mitchell, A.L.; Potter, S.C.; Punta, M.; Qureshi, M.; Sangrador-Vegas, A. The Pfam protein families database: Towards a more sustainable future. Nucleic Acids Res. 2016, 44, D279-D285. [CrossRef]

48. Gasteiger, E.; Hoogland, C.; Gattiker, A.; Duvaud, S.; Wilkins, M.R.; Appel, R.D.; Bairoch, A. Protein Identification and Analysis Tools on the ExPASy Server; Walker, J.M., Ed.; The Proteomics Protocols Handbook University of Hertfordshire: Hatfield, UK, 2005; pp. 571-607.

49. Wilkins, M.R.; Gasteiger, E.; Bairoch, A.; Sanchez, J.C.; Williams, K.L.; Appel, R.D.; Hochstrasser, D.F. Protein identification and analysis tools in the ExPASy server. Methods Mol Biol. 1999, 112, 531-552.

50. Voorrips, R.E. MapChart: Software for the graphical presentation of linkage maps and QTLs. J. Hered. 2002, 93, 77-78. [CrossRef]

51. Hu, B.; Jin, J.; Guo, A.Y.; Zhang, H.; Luo, J.; Gao, G. GSDS 2.0: An upgraded gene feature visualization server. Bioinformatics 2014, 31, 1296-1297. [CrossRef]

52. Bailey, T.L.; Johnson, J.; Grant, C.E.; Noble, W.S. The MEME suite. Nucleic Acids Res. 2015, 43, W39-W49. [CrossRef] [PubMed]

53. Chen, C.; Chen, H.; Zhang, Y.; Thomas, H.R.; Frank, M.H.; He, Y.; Xia, R. TBtools: An Integrative Toolkit Developed for Interactive Analyses of Big Biological Data. Mol. Plant 2020, 13, 1194-1202. [CrossRef] [PubMed]

54. Larkin, M.A.; Blackshields, G.; Brown, N.P.; Chenna, R.; McGettigan, P.A.; McWilliam, H.; Valentin, F.; Wallace, I.M.; Wilm, A.; Lopez, R.; et al. Clustal W and Clustal X version 2.0. Bioinformatics 2007, 23, 2947-2948. [CrossRef] [PubMed]

55. Tamura, K.; Peterson, D.; Peterson, N.; Stecher, G.; Nei, M.; Kumar, S. MEGA5: Molecular evolutionary genetics analysis using maximum likelihood, evolutionary distance, and maximum parsimony methods. Mol. Biol. Evol. 2011, 28, 2731-2739. [CrossRef] [PubMed]

56. Lescot, M.; Dehais, P.; Thijs, G.; Marchal, K.; Moreau, Y.; Van de Peer, Y.; Rouze, P.; Rombauts, S. PlantCARE, a database of plant cis-acting regulatory elements and a portal to tools for in silico analysis of promoter sequences. Nucleic Acids Res. 2002, 30, 325-327. [CrossRef] [PubMed]

57. Krzywinski, M.; Schein, J.; Birol, I.; Connors, J.; Gascoyne, R.; Horsman, D.; Jones, S.J.; Marra, M.A. Circos: An information aesthetic for comparative genomics. Genome Res. 2009, 19, 1639-1645. [CrossRef] [PubMed]

58. Gu, Z.; Cavalcanti, A.; Chen, F.C.; Bouman, P.; Li, W.H. Extent of gene duplication in the genomes of Drosophila, nematode, and yeast. Mol. Biol. Evol. 2002, 19, 256-262. [CrossRef]

59. Wang, M.; Yue, H.; Feng, K.; Deng, P.; Song, W.; Nie, X. Genome-wide identification, phylogeny and expressional profiles of mitogen activated protein kinase kinase kinase (MAPKKK) gene family in bread wheat (Triticum aestivum L.). BMC Genom. 2016, 17, 668. [CrossRef]

60. Livak, K.J.; Schmittgen, T.D. Analysis of relative gene expression data using real-time quantitative PCR and the 2(-Delta Delta $\mathrm{C}(\mathrm{T})$ ) method. Methods 2001, 25, 402-408. [CrossRef] 